\title{
NOTICIAS DE ENTALLADORES: JERÓNIMO DE VALENCIA Y CRISTÓBAL VOISIN
}

Los documentos que nos dan noticias sobre la actividad profesional realizada por los escultores-entalladores Jerónimo de Valencia y Cristóbal Voisin, no abundan; pero más escurridiza y escasa se ha mostrado la documentación que pueda aportar algún dato referente al periodo comprendido entre la fecha en que ambos maestros se conciertan en Sevilla, comprometiéndose a realizar la sillería del coro de los monjes para la iglesia de los cartujos jerezanos en $1547^{1}$, y los contratos que nos proporcionan noticias fehacientes sobre otras obras que Valencia y Voisin llevan a cabo de manera independiente, siguiendo sus respectivas trayectorias profesionales. Es esto lo que hace realmente significativo e interesante la publicación de este documento, que no sólo cubre un periodo del que se desconocían las actividades de dichos maestros, sino que nos suministra importantes datos sobre obras desconocidas de los mismos, así como la existencia en el siglo Xvi de unos términos, que aluden a elementos constructivos de las sillerías de coro, que perviven y continúan utilizándose en los siglos siguientes.

Recientemente tuve ocasión de efectuar una investigación ${ }^{2}$, sobre la sillería de coro de la Cartuja de Santa María de la Defensión de Jerez de la Frontera, de la que ambos artistas son autores. Como es sabido, la regla cartujana no permite el paso de féminas al interior de sus monasterios, circunstancia que dificultó mi trabajo. Exponíale mis quejas por este hecho al Padre Prior, y debió comprender las razones que me asistían, ya que me facilitó personalmente excelentes datos y detalles, antiguas fotografías y copias de planos realizados con motivo de la restauración de la iglesia, inventarios, etc., que me han permitido paliar esta circunstancia. Entre todo ello se hallaba la copia de un documento inédito de gran interés, que se encuentra depositado entre los restos del antiguo archivo monacal que los monjes han podido ir recuperando ${ }^{3}$. Trata dicho documento del concierto realizado en Jerez, ante escribano, entre el padre procurador del monasterio cartujo, don Baltasar de Avila y los maestros Jerónimo de Valencia y Cristóbal Voisin (Ver Apéndice Documental), y nos facilita el conocimiento de noticias interesantísimas acerca de ambos entalladores durante los años en que estuvieron trabajando en Jerez de la Frontera:

El documento confirma en primer lugar, que Jerónimo de Valencia y Cristóbal Voisin, que se definen como «maestros entalladores», y que en la fecha de concertación ( 24 de abril de 1550) estaban avecindados en Jerez en la collación de San Miguel, vecindad que, al menos, habría de alargarse durante un año. En segundo lugar, nos proporciona noticia fehaciente de la asociación de Jerónimo de Valencia y Cristóbal Voisin desde que ambos concertaron en Sevilla de mancomún la obra de la sillería del coro de la Cartuja jerezana. Su asociación se mantiene en este nuevo concierto firmado en Jerez, con un compromiso expreso de continuidad hasta el año siguiente. Asimismo se consigna la primera noticia de obra inédita -y desaparecida- de dichos maestros: los dos retablos en la iglesia del monasterio, situados «en el choro de los frayles (es decir, en el de los hermanos no profesos) fuera del choro de los monges». No cabe lugar a dudas en cuanto a la ubicación de los mismos, ya que se refiere a los dos altares que se hallaban a ambos lados de la Puerta de Entrecoros ${ }^{4}$, abierta sobre un murete que compartimenta la nave de la

\footnotetext{
1 Otorgan escritura en Sevilla, ante el escribano García de León, el 22 de septiembre de 1547.

2 López Campuzano, Julia: "La sillería del coro de la Cartuja jerezana, TRIVIUM, n. ${ }^{\circ}$ 8. Jerez de la Frontera, 1996 (en prensa).

3 El documento que me proporcionaron los monjes cartujos debe ser la copia notarial para los interesados, ya que he podido encontrar el original en el Archivo de Protocolos Notariales de Jerez de la Frontera.

4 Portada plateresca fechada en 1538 y atribuida a ambos artistas, aunque sin documentación que lo certifique. Si ello resultase cierto, constituirla la obra más antigua realizada por Jerónimo de Valencia y Cristóbal Voisin.
} 
iglesia en los espacios citados (coro de los monjes y coro de los frailes) sirviendo, asimismo, de respaldo a parte de la sillería y, por ello, claramente se expresa que han de ser «del altor de las sillas del choro de los monges».

Durante el periodo correspondiente a la fecha del documento de concertación era prior del monasterio D. Diego de Salas, que lo fue hasta el 14 de agosto de 1556, en que presenta su renuncia. Según las Notas extraídas del Protocolo primitivo y de la fundación de la Cartuja jerezana 5 "venido el dicho padre prior y reçebido por el convento desta casa luego dio orden como se acabasen los retablos de Santa Maria e San Juan y lo demas que estaua començado desde el tiempo de su anteçesor y ansi en el año 1552 años se acabo todo de labrar y se asentaron los retablos y se paso la silla del sacerdote y las puertas ya hechas y evangelisterio. Todo costo quinientos çinquenta ducados y dos años...».

En 1598, durante el priorazgo de D. Cristóbal Calvo "se hizo dorar el retablo del altar de Santa Maria y la mayor parte del retablo de San Joan». El prior D. Antonio Sánchez, elegido el 20 de julio de 1599 «acabo de dorar el retablo de San Joan»; en el mismo folio CII v. ${ }^{\circ}$ existe una nota marginal referido a este tema en la que se puntualiza: «Estos retablos, que aqui dise, no son los que de presente vemos, en este año de 1737» 6 .

Hemos de decir que con lo aquí expuesto se pone en entredicho la fecha de 1550, grabada en un sillar (Fig. 5) correspondiente al basamento de estabilización de los sitiales ${ }^{7}$, considerada hasta ahora como la data de finalización de la sillería de los monjes, obra de Jerónimo de Valencia y Cristóbal Voisin, cuya paternidad era ya conocida ${ }^{8}$. Resulta evidente que las sillas del coro estaban ya asentadas en su lugar en el momento del concierto y únicamente faltaba el elemento de unión sobre el arco de la Puerta de Entrecoros, que puede haberse instalado en 1550, en 1551 , o en 1552, dependiendo de la labor que primeramente realizaran los maestros, de todas cuantas se citan en el concierto. Contrastando la descripción que en éste se hace del elemento de trabazón ("que trabe con las dhas sillas»), con la obra real, observamos que se sigue al pie de la letra, punto por punto lo descrito (Fig. 6), faltando actualmente la jarra de azucenas por haberse perdido este panel tallado. Desconocemos el motivo por el que el arquitecto conservador D. Feliz Hernández prescindió de este elemento, (Fig. 7) ya que existe un dibujo del siglo XIX (1873), realizado antes de desmontarse la sillería para su traslado, que cuenta con la citada jarra; es posible que pudiera extraviarse o que estuviese en tan malas condiciones que fuera imposible su recuperación.

5 Esteve Guerrero, Manuel: Notas extraídas del Protocolo Primitivo..., pág. 6, Jerez, 1934.

${ }^{6}$ Esteve Guerrero, Manuel: Ibidem, págs. 10 y 11, Jerez, 1934.

En la actualidad existen unos altares a ambos lados de la Puerta de Entrecoros cuyos retablos no se corresponden con los descritos en el documento que estudiamos. Los ahora expuestos datan de 1690 según Alfonso Pleguezuelo; son de talla castellana dorada y enmarcan lienzos de mediana calidad que representan episodios de la vida de San Bruno.

Ha de tenerse en cuenta que en los siglos XVII y XVIII la iglesia del monasterio cartujo sufre grandes transformaciones para adaptarse a la estética barroca y gustos del momento además de sufrir gran expolio tras la exclaustración en 1836. Los cartujos vuelven al cenobio jerezano en 1948 y desde entonces comienza la restauración del mismo utilizándose retablos de otras procedencias, como el actual del altar mayor, procedente de la Iglesia de la Merced de Sanlúcar de Barrameda, que según C. García Peña es obra de Juan de Oviedo el Mozo fechable en 1619.

7 Este sillar se encuentra en la actualidad en el interior de la sacristía de la cartuja jerezana, formando parte del zocato de un armario de puertas talladas. La fecha 1550 aparece inscrita en el interior de una cartela tenante por dos niños.

8 Tras la exclaustración, esta sillería del coro de los monjes cartujos también salió del convento en 1873, -en 1876 se entrega la Cartuja al Ejercito (A.M.J.F. Protocolo 187, 31 de enero de 1876)-. En principio se pensó colocarla en la iglesia de San Miguel de Jerez de la Frontera, pero allí estuvo durante casi cuatro años desmantelada, antes de su traslado a la parroquia de Santiago, en la misma ciudad. Como el conjunto de sitiales era excesivo para el espacio que tenla este templo, allí se armó de manera distinta a como se exhibía originalmente -y se exhibe en la actualidad, una vez restaurada y devuelta, al cenobio- en la Cartuja de Santa María de la Defensión. Pelayo Quintero Atauri en su obra SILLERÍAS DE CORO en las iglesias españolas, Madrid, 1928, nos muestra una fotografía en la pág. 118 con la disposición que tuvo en la Iglesia de Santiago. 


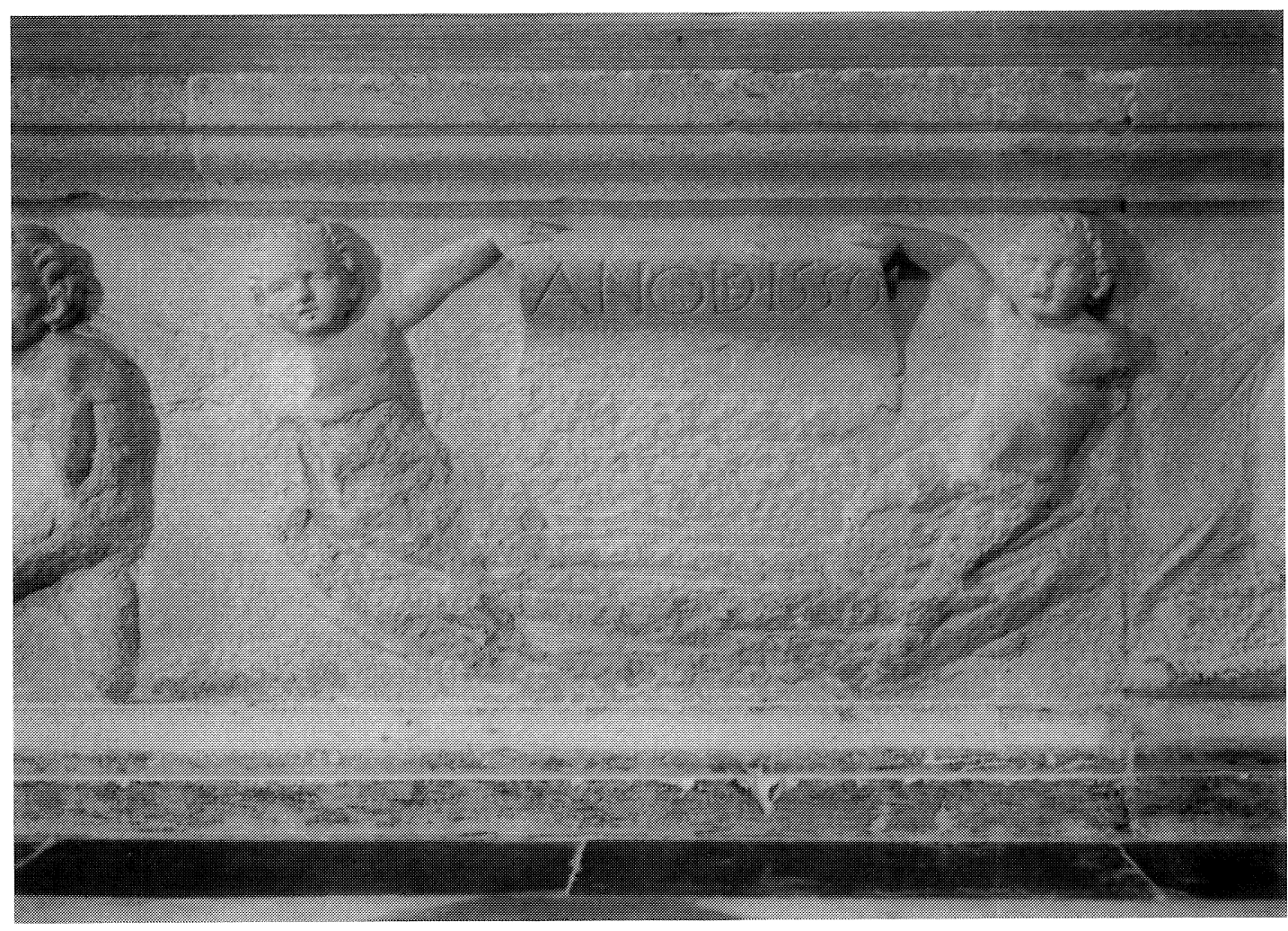

5

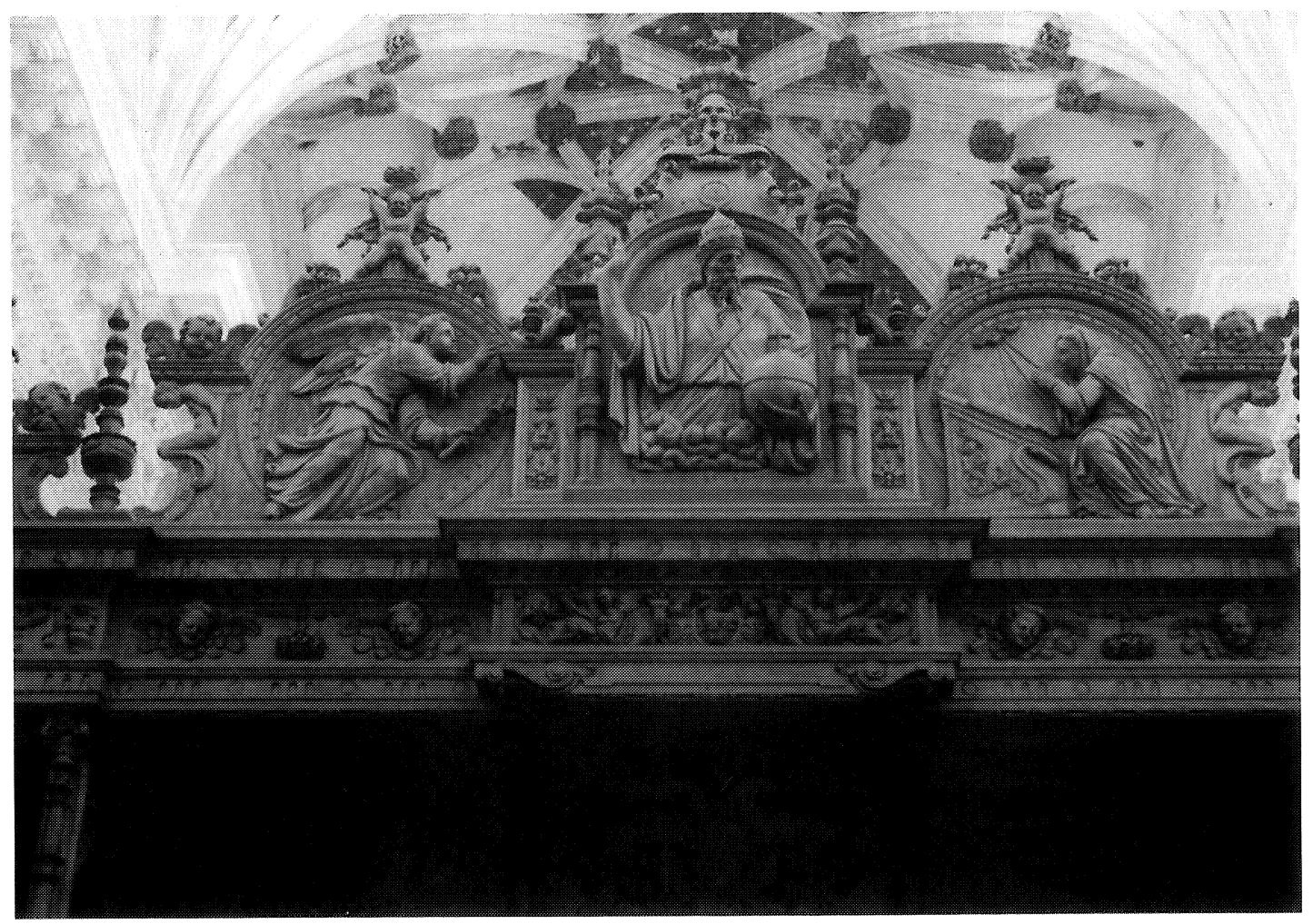

Figs. 5 y 6 . Jerónimo de Valencia y Cristóbal Voisin. Detalles de la Sillería de Coro de los Monjes. Jerez de la Frontera (Cádiz), Cartuja de Santa María de la Defensión 
También en el citado Protocolo, en el fol. CII v se dice: «El año 1552 mando -el prior D. Diego de Salas- traer de flandes un retablo de pinzel el qual (se puso en el al)tar mayor y mas de diez retablos chicos para las çellas delos monges que costaron todos puestos en esta casa 468 ducados y mas 19 maravedises y lo que se dio a geronimo de valencia que lo asento que monta 175,019». Concluye dicho folio con una nota: "Asentado este retablo y limpiada i solada la yglesia y puesto en perfecion el choro se traslado el Sanctissimo Sacramento del capitulo de los monges a la yglesia con toda solemnidad vispera de la fiesta de Todos Sanctos de mil y quinientos cinquenta y dos años..."

Asimismo se concierta una silla cátedra, de la que no se tenían noticias hasta el momento ${ }^{9}$, con una descripción minuciosa de cómo ha de ser su aspecto final, aludiendo tanto a su trazado "arquitectónico" como a los motivos propiamente ornamentales, detallando el tema que ha de representarse en el respaldo: «una figura de la resurescion tan grande quanto requiere el tablero con dos onbres armados y un sepulchro». Si nos atenemos a lo expuesto sobre el punto anterior -el perfecto reflejo de la descripción del arco que sirve como elemento de trabazón de las dos filas de sillas en la obra final asentada-, hemos de convenir en que mediante esta descripción del tema ornamental del respaldo es posible llegar a localizar este tablero (si no se ha destruido), que quizá se encuentre como obra independiente en algún templo jerezano, probablemente en las iglesias parroquiales de San Miguel o Santiago ${ }^{10}$, o tal vez en la propia Cartuja.

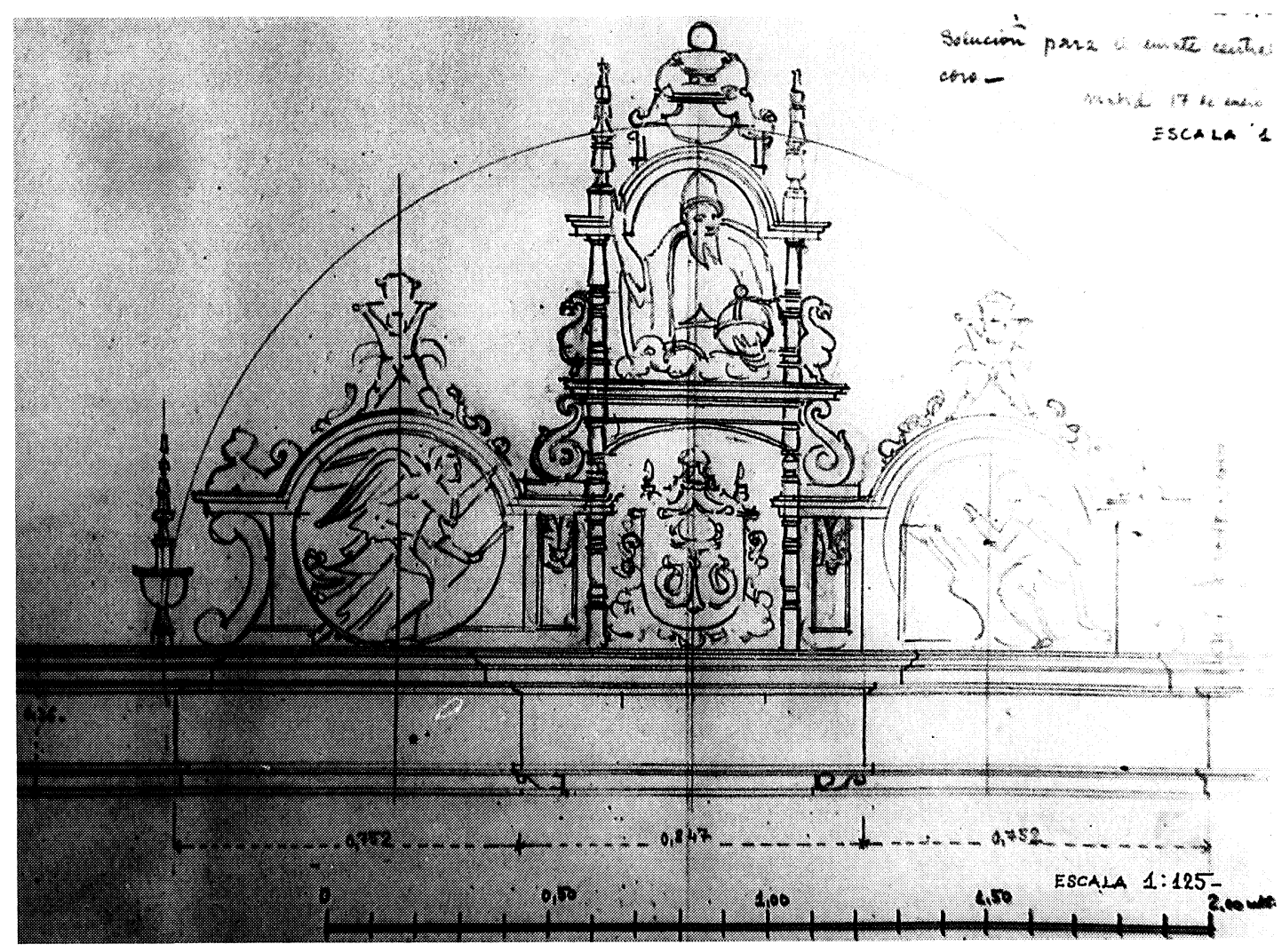

Fig. 7. Félix Hernández. Proyecto de restauración del remate de la Sillería de la Cartuja de Jerez de la Frontera.

9 En el fol. CII del Protocolo se alude a una "silla del sacerdote» que debe ser la que aquí se describe.

10 Esta hipótesis puede sustentarse por diversas razones: En primer lugar, fueron estas iglesias las que durante algún tiempo se constituyeron en depósito de la sillería. Segundo: Si no quedó el tablero en San Miguel, hubo de trasladarse con el resto desarmado de la sillería a Santiago. Allí sabemos que para adaptarse al espacio más pequeño de este templo, 
En cuanto a la forma propia de esta silla cátedra, hemos de subrayar el empleo del termino alcotores referido a los brazales del sillón, termino que se sigue utilizando durante el siglo siguiente ${ }^{11}$, en apoca barroca. Se alude también a otros trabajos menores (un evangelistero y dos puertas, que llegaron a hacer y a colocarse, según las citadas Notas...

El final del documento que transcribimos cita las condiciones del concierto, en las que el Monasterio aporta los materiales (maderas, clavazón, etc.), el transporte de los mismos y de la obra y otros trabajos de albañilería que fuesen precisos para el asentamiento de lo encargado; y los maestros, han de realizar el trabajo "hecho de su propia mano", y todas las labores se conciertan para ser realizadas y entregadas al cabo de un año; sabemos que el trabajo se alargó a dos años, pero no hubo variación en el precio estipulado, según se desprende del Protocolo, fol. CII vº.

DOCUMENTO: «Sepan quantos esta carta vieren que en la muy noble e muy leal cibdad de Xerez de la frontera veinte y quatro dias del mes de abril año del nascimiento de nuestro salvador Jesxrispto de mil e quinientos e cinquenta años en presencia de mi Ximon garcia Copin escribano $\mathrm{p}^{\circ}$ de $\mathrm{n}^{\circ}$ desta dha cibdad por su magestad e delos testigos yuso escriptos parescieron geronimo de valencia e Xrisptoual baysin maestros entalladores vecinos desta cibdad en la collacion de san miguel de la una parte e don balthasar de avila monge profeso procurador del monasterio de cartuxa que es termino desta cibdad en su nonbre de la otra, los dhos geronimo de valencia y Xrisptoual baisin de mancomun... que los dhos maestros entalladores toman a su cargo de fazer para dho monasterio las obras siguientes que an de fazer dos retablos para los altares de la yglesia de dho monasterio que están nel choro de los frayles fuera del choro de los monges los quales retablos an de ser fechos con su peana de entalladura e qada retablo con quatro istorias y quatro santos dos de qada lado grandes con su remate y coronascion las quales dhas istorias de los dhos dos retablos an de ser de media talla de la suerte quel dho monesterio e convento quisciere e todo lo demas de talla entera i que sean los dhos retablos del altor de las sillas del choro de los monges del dho monesterio e que todo sea fecho a contento del dho monesterio.

Yten an de fazer encima de la puerta del choro de los monges del dho monasterio entre las sillas de los dos coros una salutacion de nuestra señora que a deser la figura de nuestra señora y del ángel e una jarra de açuzenas en medio i todo de media talla y encima de la dha salutacion an de facer un alquitrabe e un friso e una cornisa de la obra de talla de las sillas de dho choro de los monges que trabe con las dhas sillas e segun su coronascion conforme a las sillas i en medio un dios padre y encima del dios padre su remate.

Yten que an de fazer los dhos maestros la silla cátedra del sacerdote en el choro de los monges que tenga su piedestal de talla de lo romano y encima de sus alcotores e a la parte de delante de los alcotores por encima de los mismos alcotores an de fazer unos balaustres labrados de talla mejores e mas gruesos que los de las sillas e a la parte del respaldo a de llevar sus pilares quadrados y delante delos pilares quadrados medios balaustres conforme a los de la parte de delante los quales balaustres resciban una bobeda de lo romano traçada como a los dhos maestros paresciere e encima de la dha bobeda por todos tres lados de la uanda de afuera corra su alquietrabe e friso e cornisa y encima su coronascion y encima de los balaustres en lugar de candelero an de fazer unos angeles o niños e por detrás de la coronascion an de facer una lanterna que suba alta a manera de açençario con sus arbotantes y encima su remate y en el respaldo de la dha silla an de fazer una figura de la resurrecion tan grande quanto requiere el tablero con dos onbres armados y un sepulchro.

Yten an de fazer los dhos maestros un evangelistero de talla por los lados e por delante e detrás con sus molduras con su remate y en el remate una figura que fuere señalada por el prior del dho monasterio del altor e grandor que al dho monasterio paresciere.

Yten an de fazer los susodhos una puerta para la entrada de la puerta de la canpana con sus molduras y entalladuras de una parte e de otra e la otra puerta para la sacristia de la misma obra por la faz de la yglesia.

se eliminan algunos sitiales, cuyos tableros llegaron a superponerse a algunos de los conservados como tales. El tablero de la silla cátedra debió ser (como puede observarse en otras sillerías) de mayores dimensiones que los correspondientes al resto de los sitiales, por lo que es muy probable que se reutilizase como "cuadro de devoción». Este razonamiento se basa en la utilización que, actualmente, han hecho los monjes cartujos con dos de los tableros correspondientes a respaldos de los sitiales de la citada sillería, ya que al haberse perdido los demás elementos -asientos, brazales, balaustres, etc. - se encuentran colgados de las paredes de los muros de la sacristía de la Cartuja, tras la restauración de la misma.

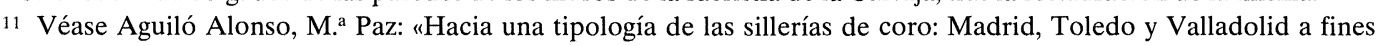
del Renacimiento", Actas del Congreso nacional Madrid en el contexto de lo Hispánico desde la época de los descubrimientos, t. I, págs. 605-620. Madrid, 1994. 
Yten que la madera que fuera menester para fazer las obras susodbas el dho monasterio sea obligado a se la dar a los dhos maestros puesta en esta cibdad donde la obieren de labrar e fecha la dba obra el dho monasterio la faga lleuar a su costa de casa de los dhos maestros al dho monasterio.

Yten que lo que tocare a albañileria para fazer sentar la dba obra la faga fazer el dho monasterio a su costa e todas las dhas obras de talla las an de fazer los dhos maestros por sus propias manos e personas sin lo cometer a otra ninguna persona e que demas de la dba madera el dho monasterio les a de dar toda la clavazon y materiales que fuera meneester que los dhos maestros no an de poner y fazer mas trabaxo de las manos lo qual an de empeszar a fazer desde oi en adelante que lo an de darr fecho e acabado dentro de un año siguiente que corre desde oi el dho dia asentado todo e fecho a perfescion a contento del dho monasterio e monges del, e por las manos e trabajo de todo ello les a de pagar el dho monasterio y el dho don baltasar de avila se obligo que les dara e pagara a los dhos maestros quinientos e cinquenta ducados de oro de a tres cientor e sesenta e cinco maravedis qada uno los quales dho don baltasar quedo que les serán dados e pagados treynta ducados en qada una bez en dho año e que les fara la primera paga primero dia del mes de marzo primero que viene deste presente año de la fecha desta carta e asnsi dende en adelante al principo de qada mes los otros treynta ducados e lo que restare de lo susodho en el dho tienpo le a de pagar el dho monasterio a los susodho maestros acabada la dba obra e que si acabada la dba obra el dho monasterio no quedare satis fecho de la dha obra o de alguna parte della que el dho monasterio nombre dos oficiales de dho oficio de qualquier parte que el diho monasterio quisiere los quales a costa de anbas partes y bajo de iuramento vean la dha obra e si declararen que las manos e trabaxo de dha obra no merescen los dhos quinientos e cinquenta ducados que lo que menos declararen que meresca se les defalque del dho prescio e si lo tuvieren rescibido restituyan los dhos maestros al dho monasterio luego e si declararen que merescia mas de los dhos quinientos e cinquenta ducados que el dho monasterio sea obligado e dho don baltasar a les pagar la demasia e que asimiesmo los dhos oficiales bean si la dba obra tiene alguna cosa mal fecha que lo siguren estar mal fecho los dhos maestros la fagan de buena obra e a su costa como los dhos oficiales lo declararen e demas del prescio susodho les a de dar el dho monasterio para ayuda de costa un cahiz de trigo e dos arrouas de azeite luego que los susodhos quiscieren ser pagados dello e desta manera los dhos maestros debajo de la dha mancomunidad en su nombre se obligan el dho don baltasar de avila se obliga en nonbre del dho monasterio e anbas partes se obligaron pagar por esta escriptura de concierto e no se salir ninguno afuera e los dhos maestros de non dexar de facer la dha obra y no leuantar la mano della y asta lo acabar e si no lo fizieren que el dho monesterio a costa de dhos maestros faga facer y acabar la dha obra...

...e en testimonio dello otorgaron la presente ante mi el dho escribano $\mathrm{p}^{\circ}$ e testigos y uso escritos en la dha cibdad de Xerez de la frontera en la casa bodega del dho monasterio en el dho dia mes i año susodho e los dhos otorgantes lo firmaron de sus nonbres en el registro testigos que fueron presentes el bachiller antonio de Cuenca, anton garcia Copin escribano de Xerez e francisco hernandes criado del dho monasterio vecinos desta cibdad.

= Balthasar de Avila $=$ Geronimo de Valencia $=$ Xristofle
Voisin = Ante mi = Ximon Garcia Copin escribano publico.»

Por JULIA LÓPEZ CAMPUZANO

Universidad Complutense de Madrid

\section{NUEVA APORTACIÓN DOCUMENTAL SOBRE EL SAN JUAN BAUTISTA DE MARTÍNEZ MONTAÑÉS \\ (Iglesia conventual de Santa Ana de Sevilla)}

En el hermoso templo de carmelitas de clausura del monasterio de Santa Ana de Sevilla existe una talla de San Juan Bautista que sólo modernamente ha cobrado actualidad. La atribución de los historiadores y críticos del arte a autores varios indica un poco el misterio en el que estuvo envuelta. 